\title{
VERACIDAD EN LOS NAUFRAGIOS: \\ LA TÉCNICA NARRATIVA DE \\ ALVAR NÚÑEZ CABEZA DE VACA
}

POR

\author{
JuAN Francisco MaURa \\ The University of Vermont
}

Si se observa el motivo que empujó al autor de los Naufragios a escribir su obra, se percibirá que no fue un fin estético o literario, aunque la obra posea estas características, sino uno intencional y premeditado. ${ }^{1}$ De cualquier manera, en su discurso supo atraer al destinatario a quien estaba dirigida. Se podría argumentar que ya de por sí el fin pragmático de la obra le resta calidad literaria por no obedecer a impulsos altruísticamente artísticos o estéticos, sino por el contrario, pragmáticos e interesados. Sin embargo, no es éste el caso. ${ }^{2}$ Es sabido que Cabeza de Vaca, una vez presentada su versión de los hechos, consigue del emperador Carlos V los títulos de Adelantado, Gobernador y Capitán General del Río de la Plata. Habría que plantearse, por lo tanto, si toda la construcción narrativa de su relato no es otra cosa que una cuidada elaboración de situaciones ficticias y sobrenaturales, combinadas magistralmente con hechos y descripciones reales de las tierras por donde anduvo con otros tres compañeros. Él es el exclusivo dueño y señor del eje en donde gira toda su "crónica". La "Relación Conjunta" del cronista oficial de Indias, Gonzalo Fernández de Oviedo, es la primera en darnos de primera mano "quejas" del testimonio presentado en la obra de Cabeza de Vaca: "Ni quiero consentir al Cabeza de Vaca el nombre que en su impresión da a aquella isla, que llama de Mal Hado, pues en la primera relación no le

\footnotetext{
${ }^{1}$ Todavía existe una fuerte resistencia a poner en duda la información vertida en los Naufragios. Véase el interesante artículo del profesor Pupo-Walker, "Pesquisas para una nueva lectura de los Naufragios de Alvar Núnez Cabeza de Vaca", Revista Iberoamericana 53 (1987): 517-539. El profesor Pupo-Walker amplía la visión de Cabeza de Vaca como "mártir" en Naufragios a la manera de la literatura hagiográfica medieval, aunque no admita que este paralelismo se produzca deliberadamente (522). Por mi parte defiendo que la aparente estructura historiográfica, al modo de "crónica" con elementos informativos - en su mayor parte falsos-sobre la etnografia, fauna y flora sólo son una coartada para que el autor pueda presentar en su narración un "todo" coherente con su propia conveniencia. De igual forma la obra de Alvar Núnez, no es una obra aislada en este sentido, forma parte del grupo de "Novelas de Naufragios" especialmente comunes en España y Portugal en su época. Véase mi edición crítica de los Naufragios (Madrid: Ediciones Cátedra, 1989). Se cita por esta edición.

${ }^{2}$ Véase el excelente artículo de Robert Lewis sobre este asunto. "Los Naufragios de Alvar Núñez: historia y ficción", Revista Iberoamericana 120-121 (1982): 681-694.
} 
pusieron nombre ni él se lo puede dar ...". ${ }^{3} \mathrm{Al}$ analizar la repercusión que ha tenido la obra en la sociedad de su tiempo, como en la actual, sorprende la enorme atracción que para el lector tiene el protagonista. La identificación con éste es directa y constante. A pesar de todo, no narra ningún suceso histórico de relevante importancia, sino las puntuales descripciones de la etnografia, flora y fauna, de las que el autor sabrá sacar tan buen provecho.

Beatriz Pastor limita la obra enormemente, en su ensayo Discurso narrativo de la conquista de América, al sólo ver a Cabeza de Vaca como el portador de posturas ideológicas o políticas y comparar su actitud hacia el indígena con la atribuida al padre las Casas, entre otros. ${ }^{4}$ No comparto con ella la imagen de Alvar Núnez como "desmitificador" de la figura del conquistador. Es mucho más fácil identificarse con el mártir que con el romano, en este caso, con un teórico defensor del indio antes que con el conquistador. ${ }^{5}$ Rolena Adorno, de igual manera y basándose en la imagen "anticonquistadora" que da Pastor de Cabeza de Vaca, dice lo siguiente:

The success of Cabeza de Vaca's writing can be explained by the fact that it took a counter-conquest position. That is, Cabeza de Vaca advocated peaceful conversion of the natives and demonstrated that good treatment of the Indians produced results that served both the well-being of native populations and the economic interest of the Spaniards (220).

Sin embargo, Alvar Núñez nunca llegó a demostrar nada fuera de su testimonio escrito. Como se puede observar, incluso en la crítica más reciente, todavía hoy se sigue ciegamente la información ofrecida por Alvar Núnez en sus Naufragios. Pero esta aparente visión cristiana y filantrópica presente en los Naufragios, una de las obras más entretenidas y apasionantes de las escritas en su género en el siglo XVI, no concuerda con los hechos de la vida de Cabeza de Vaca. Poco tiempo después de su regreso a España, Cabeza de Vaca ya estaba en la Corte intentando conseguir el favor real para una nueva empresa, esta vez, bajo su mando. Efectivamente, consiguió la Gobernación y la Capitanía General del Río de la Plata, y no precisamente para seguir haciendo de "martir", sino para sojuzgar a los indios rebeldes e imponer su autoridad frente a sus compatriotas. En las "Capitulaciones" entre la Corona y él, queda bien clara la condición por la cual se le otorgarán los mencionados privilegios. Pero lo más importante de este documento es el hecho de que a Cabeza de

${ }^{3}$ Gonzalo Fernández de Oviedo, Historia General y Natural de las Indias, Islas y Tierra Firme del Mar Océano, Volumen 3, libro 25 (Madrid: Editado por D. José Amador de los Rios, 1853) 582.

${ }^{4}$ Véase Beatriz Pastor, Discurso Narrativo de la Conquista de América (La Habana: Ediciones Casa de las Américas, 1983) 329. Véase también Rolena Adorno, "The Discursive Encounter of Spain and America: The Authority of Eyewitness Testimony in Writing History", The William and Mary Quarterly 49 (1992): 210-228.

${ }^{5}$ Hablar de Alvar Núnez como el desmitificador de la figura del conquistador por "excelencia" es una opinión un tanto arriesgada. Si Cabeza de Vaca se pasea desnudo y tiene relaciones con los indios de "igual a igual" no es por su propio gusto. Hay que inclinarse más a pensar que si él hubiese tenido la oportunidad de ser un "Cortés" o un "Pizarro" no habría dudado un sólo momento en aprovecharla. Es más, utilizará su "desnudez" y su "martirio" tan magistralmente que será "vestido" con los títulos de Adelantado, Gobernador y Capitán General. 
Vaca se le mande de "conquistador", con el título de "Adelantado" de las tierras que "conquistará y poblará", así como beneficiario de las rentas de las nuevas tierras que descubriera. ${ }^{6}$

El no haber tenido hasta la fecha al alcance de la mano documentos para cotejar lo que nos "cuenta" Alvar Núñez en su obra con lo que realmente pasó, ha hecho que muchos hayan tomado su palabra escrita como definitiva. El texto en sí mismo fue testimonio histórico suficiente para el lector de entonces como ha sido para el de ahora, pese a lo fantástico y contradictorio de la narración. La "información" - autobiográfica y textualque aparece en los Naufragios, se ha tenido por válida hasta el presente.

Pero el descubrimiento de nueva información en los últimos años ha cambiado en cierta forma la contextura tradicional y humana en que ha sido visto el autor y su obra. Cuando se analizan los Naufragios, se vislumbra que el protagonista y narrador de la obra no responden al mismo patrón. Uno es una continua imitación de Jesucristo en el Nuevo Mundo. El otro es un personaje en que lo picaresco asoma, una vez conocidos algunos antecedentes de su vida personal. Al poco tiempo de ser proclamado gobernador del Río de la Plata, Alvar Núñez mandó publicar un pregón para que los oficiales reales hiciesen fabricar un hierro para marcar a los esclavos traídos de España. Se sabe que entre estos esclavos había cristianas blancas, y que algunas fueron herradas en la cara. ${ }^{7}$

En los documentos que tuve la oportunidad de encontrar en el Archivo Ducal de Medina Sidonia durante los veranos de 1985 y 1986, especialmente en aquél que trata de la supuesta impotencia sexual del Duque de la Casa antes citada, se puede ver el carácter picaresco de Cabeza de Vaca. ${ }^{8}$ El mencionado "camarero" no es otro que el mismo que se hará pasar unos años más tarde por un "Apóstol de las Indias", convenciendo así al entonces emperador, Carlos V, de la importancia por él realizada en el continente americano. Vale la pena volver a citar algunos fragmentos de dicho documento:

Procesos y autos seguidos sobre la nulidad de matrimonio de los Sres. Duques D. Alonso
y Da. Ana de Aragón...

En el tiempo que se acostaban juntos los Duques, preguntó a Alvar Núñez Cabeza de Vaca, camarero del Duque, el cual era primo de Fuentes "y muy su amigo", si el Duque tenía parte carnal con la Duquesa. Y Alvar Núnez respondió que sí tenían. Y preguntó a Alvar si lo había visto. Y Alvar dijo que no, pero que las camisas que se desnudaba el Duque venían sucias y llenas de simiente de varón, e que por esto creía e tenía por cierto el dicho Alvar Núnez. Le dijo Fuentes que aquello no era testigo de fe, porque podía ser aquella simiente hecha por poluciones y por otras maneras. Y cree que al fin Alvar Núnez le dijo que no dudase de ello. Nadie ni Alvar Núnez le dió más particularidades sobre el tema. Alvar Núñez fue muerto en las Indias y no recuerda cuando se lo dijo.

Vio un día que el Duque tenía su natura alzada algo, estándole atando las calzas el camarero, e que esto no sabe si era por tener ganas de orinar o si era de su natural de

\footnotetext{
${ }^{6}$ Archivo General de Indias, Indiferente General. Legajo 415, folio 150.

7 Juan Francisco Maura, "Esclavas españolas en el Nuevo Mundo: una nota histórica", Colonial Latin American Historical Review 2 (1993): 188-89.

${ }^{8}$ Archivo Ducal de Medina Sidonia, Sanlúcar de Barrameda, Legajo 937.
} 
querer alzar como hombre. Estaban presentes el camarero Alvar Núfiez e Inigo de Guzmán, e todos rieron de ello. Preguntando porqué se reían dijo que porque este testigo nunca le había visto de aquella arte. Preguntado "en que posesión lo tenían", dice que como hombre que no hiciera aquello, e que por esto se rieron de ello. Vió esto dos o tres años después de casado el Duque (Juan de Lasarte).

Siendo camarero del Duque Alvar Núnez Cabeza de Vaca, él y este testigo quedaron en meter una mujer al Duque después de casado estando acostado en la cama. Y que esta mujer venía limpia y olorosa y con camisa limpia para que hubiera acceso a ella, para ver si era potente, y la dicha mujer dijo que ella trabajaría con el Duque para que oviera parte con ella. Y que este testigo y el dicho camarero Alvar Núñez, que es ya difunto, dejaron a la mujer con el Duque dentro de la cámara y cerraron la puerta, y se pasaron a escuchar. $Y$ que entonces este testigo y el camarero oyeron como el Duque daba voces y lloraba diciendo:

- ¡Déxame Dola! ¡Al diablo Dola! ¡Al diablo! y que ella lo alagaba y hablaba amorosamente, e él no por eso dexaba de decir que se fuese, e que entonces la mujer salió a la puerta e se la abrieron e dixo al camarero e a este testigo:

— En hora tal me metiste acá! Que no aprovechaba nada. Que no es para nada.

Este testigo, con Alvar Núñez Cabeza de Vaca, que es ya difunto e Villavicencio, e Juan de Vera, hermano de Alvar Núnez que así mismo cree que es ya difunto, y otros como deseaban mucho que el Duque fuese hombre para llegar a la Duquesa, echaron al Duque dos o tres mujeres en diversos tiempos, las cuales e cada una de ellas lo tomaban, lo besaban e lo abrazaban, e tomaban su miembro con la mano e se lo trataban e lo traían e incitaban sin provecho. "E que no era sino una mujer como ellas" (Juan Manuel Olando). ${ }^{9}$

Este documento amplía enormemente la dimensión biográfica del protagonista. Resulta interesante observar, como a medida que van apareciéndo nuevos documentos sobre la vida del autor, sus experiencias personales superan en muchos casos en "fabulosas" a las aparecidas en su propia obra. Esperemos que con la información que vaya apareciendo se pueda terminar de reconstruir este maravilloso rompecabezas sobre su vida.

A través de otra obra autobiográfica contemporánea, se tiene noticia de la mencionada impotencia del duque de Medina Sidonia. En el Libro de la Vida y Costumbres de don Alonso Enriquez de Guzmán, caballero y aventurero típico del siglo XVI, obra que ofrece algunas semejanzas con la de Alvar Núñez - autobiográfica picaresca, teóricamente documental-, pero que a su vez dista mucho en su concepción y estilo, se hace una alusión a la referida "impotencia".

Este don Juan Alonso a quien se escribe esta carta es hermano segundo, primogénito del duque de Medina Sidonia, el cual fue menguado de juicio y de potencia, sin poder ni saber tener acceso a mujer, por lo cual la que había de ser su amada, dona Ana de Aragón, nieta del rey de Aragón y de Castilla, don Hernando Católico de gloriosa memoria ... Los cuales se casaron y governaron este estado cuerda y sabiamente como cristianos

9 Alvar Núñez, al tiempo de este proceso, no era "difunto" como algunos pensaban, sino que se encontraba por tierras americanas. Este proceso, sobre la nulidad de matrimonio de los referidos duques, se llevó a cabo en Sevilla entre 1532 y 1537. 
servidores de su Rey. Y así efectuaron su casamiento con consentimiento del Papa, los cuales hicieron todas sus diligencias para ver si era justo, como fue. ${ }^{10}$

En esta obra, se presenta además de las andanzas del autor por el Perú y su participación en las luchas internas entre Almagro y Pizarro, el mundo cortesano, las intrigas y penalidades por las que tiene que pasar un hidalgo de "buena cuna" para poder ser "reconocido".

Alvar Núnez tuvo mucha suerte a la hora de presentar sus experiencias y servicios ofrecidos a su rey. Sin embargo, querer poner la etiqueta de crónica histórica a la narración de un tesorero, superviviente de una expedición que acabó en naufragio, es querer estirar la "verdad" hasta sus límites. No porque no haya habido otros narradores que relatasen episodios referentes a la conquista de América, sino porque Alvar Núnez es protagonista y autor de una obra en la que su propia supervivencia - ya que la de sus compañeros apenas es tenida en cuenta - será lo único que pueda traer consigo. Lógicamente si su fin era conseguir un favor del monarca, tendría que sazonar su "relación" con palabras como oro, esmeraldas, así como una detalladísima descripción de las gentes, tierras y costumbres de las personas con las que se encontró. Se puede dudar de su información; la cantidad de información que se da a veces sobrepasa los límites de la verosimilitud. A fin de cuentas, es un ser que pasó casi nueve años sin ninguna otra forma de obtener datos más que en su propia memoria. Y no porque la tuviera mala, ni mucho menos, no en vano fue tesorero lo que lógicamente hace pensar que entendería de cuentas-, sino que además fue hombre de confianza del duque de Medina Sidonia en cuestiones financieras.

11-12-1522. Jueves. El Duque otorga poder a Alvar Núñez Cabeza de Vaca, su camarero, para que en su lugar y en nombre de su señoría pudiese sustituir otro poder, que antes de éste había otorgado al dicho Alvar Núñez, para que en nombre del Duque pudiese comparecer ante los contadores de SM, que tienen a su cargo los libros de los maestrazgos órdenes, e pedir sacar cualquier libranza de los maravedís que le son debidos que los tienen en dichos libros con el hábito del señor de Santiago que son 12000 maravedís cada año."

Este genial andaluz ha sabido cómo usar su imaginación para granjearse la admiración y sorpresa de los lectores hasta nuestros días. Parece francamente inexplicable que hasta este momento todavía sean muchos los que crean y defiendan la autenticidad de los hechos y extraordinarias experiencias aparecidos en los Naufragios. ${ }^{12}$ Parece como si existiera la necesidad de mantener el mito vivo, mantener al "Caballero de la Triste Figura" por encima de la imagen de su autor. Pero para creer, hace falta fe, y Alvar Núnez no la proporciona como “Apóstol de las Indias" aunque sí como novelista. Novelista por propia conveniencia. Los ejemplos de la resurrección de un muerto y de la operación quirúrgica son nada menos

\footnotetext{
${ }^{10}$ Alonso Enríquez de Guzmán. Libro de la Vida y Costumbres de don Alonso Enríquez de Guzmán (Madrid: Atlas, 1960) 113.

"Archivo Ducal de Medina Sidonia, Legajo 937.

${ }_{12}$ Robert Lewis, "Los Naufragios de Alvar Núnez como construcción narrativa". Kentucky Romance Quarterly 25 (1978): 27-37. Henry Wagner, The Spanish Southwest 1542-1794. (Albuquerque: The Quivira Society, 1937). Serían las más sobresalientes excepciones en los últimos tiempos.
} 
que formidables. La habilidad de exposición de los sucesos acompañados siempre de una probanza para autentificar su "verismo" hace de Alvar Núñez un maestro en este difícil arte.

Son numerosas las ocasiones donde el explorador andaluz introduce elementos extraordinarios o sobrenaturales - Mala Cosa, el milagro de la resurrección, el árbol ardiendo que se encuentra cuando anda perdido, profecías, operaciones quirúrgicas, etc. Dentro de éstas, merece la pena destacar la operación que le hace a un indio para sacarle una punta de flecha situada junto al corazón. El incidente en sí llama la atención por lo difícil de ejecutar, sobre todo, no teniendo los instrumentos necesarios para llevar la operación a cabo. Sin embargo, no es el incidente "per se" lo que impresiona al lector por llevarse a buen término, sino la capacidad del autor de adjudicarse propiedades milagrosas, yendo más lejos de lo que podríamos considerar "natural", o incluso, "científico". Cabeza de Vaca sabrá conmovernos con su detallada y minuciosa descripción de la operación que va a llevar a cabo. Todos sus utensilios no serán más que un cuchillo de cocina para operar y un hueso de venado para darle los puntos una vez sacada la flecha. No es eso todo. Lo curioso aquí es observar como después de esta dificilísima operación, hecha únicamente con un cuchillo, la cicatriz que le dejará apenas se podrá comparar con las rayas de la palma de la mano. Por otro lado, por la descripción, se deduce que fueron sólo unas horas las que pasaron para que la herida pudiese cicatrizar.

Aquí me trajeron un hombre e me dijeron que había mucho tiempo que le habían herido con una flecha por la espalda derecha, y tenía la punta de la flecha sobre el corazón; decía que le daba mucha pena e que por aquella causa siempre estaba enfermo. Yo le toqué y sentí la punta de la flecha vi que la tenía atravesada por la ternilla, y con un cuchillo que tenía le abrí el pecho hasta aquel lugar y vi que tenía la punta atravesada y estaba muy mala de sacar; torné a cortar más y metí la punta del cuchillo y con gran trabajo se la saqué. Era muy larga y con un hueso de venado; usando de mi oficio de medicina le di dos puntos, y dados se me desangraba, y con raspa de un cuero le estanqué la sangre e, cuando huve sacado la punta, pidiéronmela e yo se la di, y el pueblo todo vino a verla y la embiaron por la tierra adentro para que la viesen los que allá estaban, y por esto hicieron muchos bailes y fiestas como ellos suelen hacer. Y otro día le corté los dos puntos al indio y estaba sano y no parescía la herida que le había hecho sino como una raya de la Palma de la mano, y dijo que no sentía dolor ni pena alguna (Cabeza de Vaca, 138; capítulo 29).

Viene a cuento esta cita, dado que todavía se tienen como auténticos este tipo de testimonios del hidalgo jerezano. A Cabeza de Vaca se le tiene por lo que él mismo retrata de sí en su obra. No en vano se le ha calificado como "El primer cirujano de Texas" y otra serie de calificativos por el estilo: "When Texas Surgical Society was celebrating its 25th anniversary in 1940, Dr. Walter G. Stuck commented in a newsletter that Cabeza de Vaca, who was doing surgery 380 years earlier, might justly be considered 'our direct forebear'". ${ }^{13}$

\footnotetext{
${ }^{13}$ Nancy Hamilton, "Painting Depicts Cabeza de Vaca, First Texas Surgeon", Texas Times (MayJune 1983): 2.
} 
La maestría con que el autor inserta elementos mesiánicos procedentes directamente de la Biblia, por supuesto, sin hacer ninguna alusión a ésta en ningún momento, debilita las defensas de nuestro sentido común, dejando pasar cierta información que en circunstancias diferentes nunca se nos ocurriría aceptar. En el caso del "árbol ardiendo" y "las seis lenguas" de las que se hace sabedor, se puede trazar un paralelismo directo con las sagradas escrituras. Casi al comienzo del libro del Éxodo, en la Biblia, Dios se le aparece a Moisés en la forma de una zarza ardiendo:

Apacentaba Moisés el ganado de Jetró, su suegro, sacerdote de Madián. Llevóle un día más allá del desierto; y llegado al monte de Dios, Horeb, se le apareció el ángel de Yavé en llama de fuego en medio de una zarza. Veía Moisés que la zarza ardía y no se consumía, y se dijo: "Voy a ver que gran visión es ésta y por qué no se consume la zarza". Vio Yavé que se acercaba para mirar, y le llamó de en medio de la zarza: "¡Moisés, Moisés!" El respondió: "Heme aquí". Yavé le dijo: "No te acerques. Quita las sandalias de tus pies, que el lugar en que estás es tierra santa"; y añadió: "Yo soy el Dios de tus padres, el Dios de Abraham, el Dios de Isaac, el Dios de Jacob". Moisés se cubrió el rostro, temía mirar a Dios (Exodo 3, 1-6)..$^{14}$

Se observará cómo el autor, insertando este tipo de fragmentos bíblicos, podrá ir consolidando paulatinamente su dimensión mesiánica. Véase la semejanza con la obra del "Nuevo Mesías".

y aquella noche me perdí, y plugo a Dios que hallé un árbol ardiendo y al fuego dél pasé aquel frío aquella noche, y a la mañana yo me cargué de leña y tomé dos tizones y volví a buscarlos, y anduve desta manera cinco días, siempre con mi lumbre y carga de leña, porque si el fuego se me matase en parte donde no tuviese leña, como en muchas partes no lo había, tuviese que hacer otros tizones y no me quedase sin lumbre, porque para el frío yo no tenía otro remedio, por andar desnudo como nascí (Cabeza de Vaca 108; capítulo 21).

Se destaca la figura del "héroe cristiano" en su perseverancia y fe en Dios por conseguir sobrevivir.

En la Biblia, en los "Hechos de los apóstoles" encontramos cómo el Espíritu Santo da poder a los apóstoles para expresarse en diferentes lenguas:

Al cumplirse el día de Pentecostés, estando todos juntos en un lugar, se produjo de repente un ruido proveniente del cielo como el de un viento que sopla impetuosamente, que invadió toda la casa en que residían. Aparecieron como divididas, lenguas de fuego, que se posaron sobre cada uno de ellos, quedando todos llenos del Espíritu Santo; y comenzaron a hablar en lenguas extrañas, según que el Espíritu Santo les otorgaba expresarse (Hechos de los Apóstoles 2, 1-5).

Recuérdese que Alvar Núnez, a su vez, se hace sabedor de "seis" lenguas que dice aprender durante el tiempo que pasó con las diferentes tribus indias. Verdad o no, el

\footnotetext{
${ }^{14}$ Se cita por la edición de la Biblia (Madrid: Editorial Católica, 1986).
} 
paralelismo es constante y no es extraño considerando el propósito original que movió al autor a escribir su obra.

Pasamos por gran número y diversidades de lenguas; con todas ellas Dios nuestro Señor nos favoreció, porque siempre nos entendieron y les entendimos; y ansí, preguntábamos y respondían por sefias, como si ellos hablaran nuestra lengua y nosotros la suya; porque aunque sabíamos seis lenguas, no nos podíamos en todas partes aprovechar de ellas, porque hallamos más de mil diferencias (Cabeza de Vaca 151; capítulo 31).

A falta de factores económicos que llamasen la atención, a pesar de nombrarse el oro y las esmeraldas en unas cuantas ocasiones, el autor de los Naufragios tiene que recurrir a otros elementos sustitutivos que mantengan el interés de quien va a leer la obra. La conversión de los indios por un lado — de ahí su función apostólica- y la descripción pormenorizada de gentes y territorios por otro. Todo ello con tal nivel de precisión, que es difícil creer en la exactitud de datos, nombres, fechas, cantidades, distancias e incluso número de lenguas, como vimos antes, de las que se hace sabedor.

El profesor Pupo-Walker es consciente de esta estrecha relación entre los hechos de Cabeza de Vaca y los hechos de los santos, a pesar de no dar el carácter de "deliberado" a las insertaciones de Alvar Núñez:

Pero al constatar estos hechos, entiéndase que no he querido inferir que Cabeza de Vaca haya articulado deliberadamente en sus Naufragios elementos concretos del código hagiográfico. Lo que pretendo demostrar, en las páginas que siguen, es que su texto como entidad escritural y transmisora recupera e integra componentes de esa tradición hagiográfica y legendaria; tradición convocada en estas instancias por un registro de asociaciones que son culturalmente inherentes al peregrinaje que Alvar Núñez nos describe (Pupo-Walker 522).

No comprendo por qué todavía se le da a Cabeza de Vaca esa aureola de santidad: "cuando litigaba vigorosamente contra las injusticias que le impuso el Consejo de Indias" (Pupo-Walker 518). En los documentos que se poseen en el Archivo General de Indias del proceso hecho en su contra, no queda demostrada en ningún momento la "inocencia" de Alvar Núñez en los hechos que ocurrieron en su viaje al Río de la Plata. ${ }^{15}$ Todo hace pensar que la fuerza de la obra - Naufragios - y la imagen que el autor mismo se da en ésta, ha transcendido hasta la fecha, existiendo una resistencia a aceptar todo aquello que vaya en su contra.

En oposición a la opinión del señor Pupo-Walker, pienso que todo este tipo de insertaciones mesíanicas y hagiográficas son totalmente deliberadas. La narración de Alvar Núñez Cabeza de Vaca posee, por lo tanto, todo el atractivo de las crónicas del Nuevo Mundo, hecha por un testigo presencial, con el complemento de poseer toda la magia y atracción que lo novelesco aporta al relato. Es hora ya de ver la capacidad literaria y novelística del autor de los Naufragios y no tomar la obra como un documento fehaciente

${ }^{15}$ Archivo General de Indias, Indiferente General, Legajo 415. Justicia, Legajos. 1130, 1131, 1132. Patronato, Legajos. 18, 20, 29. 
de la experiencia vivida de un superviviente a través de los territorios del suroeste de los actuales Estados Unidos. Alvar Núñez logró fama y honores, no por sus hechos, ya que fueron varios los que compartieron sus experiencias, sino por la manera de narrarlos. No fueron sus sorprendentes aventuras a través de los territorios recorridos, la información presentada sobre éstos, los sucesos extraordinarios o los "milagros" efectuados, que tanto sorprendieron en su tiempo, sino la manera de pasar al papel aquello que tanto impresiona hoy, no solamente por lo "maravilloso", sino por la habilidad e inteligencia con que fue escrito. 
